\title{
Prolonged Mechanical Ventilation as a Predictor of Mortality After Cardiac Surgery
}

\author{
Maria Dolores Fernandez-Zamora MD, Antonio Gordillo-Brenes MD, Esther Banderas-Bravo MD, \\ José Andrés Arboleda-Sánchez MD, Rafael Hinojosa-Pérez MD, Eduardo Aguilar-Alonso MD, \\ Ángel Herruzo-Aviles MD, Emilio Curiel-Balsera MD, Ángel Sánchez-Rodríguez MD, \\ Ricardo Rivera-Fernández MD, and the ARIAM Andalucía Group
}

\begin{abstract}
BACKGROUND: Mortality among the small percentage of cardiac surgery patients receiving prolonged mechanical ventilation is high, but this issue appears to be inadequately addressed in guidelines. METHODS: This study is a retrospective analysis of prospective, multi-center, and observational study in Spain including all adults undergoing cardiac surgery in 3 Andalusian hospitals between June 2008 and December 2012. RESULTS: The study included 3,588 adults with mean \pm SD age of $63.5 \pm 12.8 \mathrm{y}$ and with median (interquartile range) EuroSCORE of 5 (3-7) points. Prolonged mechanical ventilation ( $>24 \mathrm{~h}$ ) was required by 415 subjects $(11.6 \%)$, with ICU mortality of $44.3 \%$ (184 subjects), and was not required by 3,173 subjects (88.4\%), with ICU mortality of $3.1 \%$ (99 subjects, $P<.001$ ). Prolonged mechanical ventilation was associated with more complications and was required by $4.5 \%$ of subjects with a EuroSCORE <5, $11.2 \%$ with a score of $5-7,27.2 \%$ with a score of $8-10$, and $32.2 \%$ with a score $>10$. In the multivariable analysis, ICU mortality was associated with illness severity, duration of bypass surgery, surgery type, and prolonged mechanical ventilation (odds ratio 15.19, 95\% CI 11.56-22.09). The main cause of death was multiple organ failure and sepsis in subjects who required prolonged mechanical ventilation $\mathbf{5 0 . 3 \%})$ and cardiogenic shock in those who did not $\mathbf{5 9 . 2 \% )}$. CONCLUSION: Prolonged postoperative mechanical ventilation was required by $10-20 \%$ of cardiac surgery subjects, who constitute a specific group that represents most of the postoperative mortality, which is associated with multiple organ failure and sepsis. Key words: cardiac surgery; mechanical ventilation; mortality; severity. [Respir Care 2018;63(5):550-557. (C) 2018 Daedalus Enterprises]
\end{abstract}

\section{Introduction}

A large number of ICU admissions are for cardiac surgery patients. Their mortality rate is not very high overall, but this rate is markedly increased in patients with surgical complications and poor presurgery health, as reported by

\footnotetext{
Drs Fernandez-Zamora, Banderas-Bravo, Arboleda-Sánchez, and CurielBalsera are affiliated with the ICU at Hospital Regional Carlos Haya, Málaga, Spain. Drs Gordillo-Brenes and Sánchez-Rodríguez are affiliated with the ICU at Hospital Puerta del Mar, Cádiz, Spain. Drs Hinojosa-Pérez and Herruzo-Aviles are affiliated with the ICU at Hospital Virgen del Rocio, Sevilla, Spain. Dr Aguilar-Alonso is affiliated with the ICU at Hospital Infanta Margarita, Cabra, Córdoba, Spain. Dr Rivera- Fernández is affiliated with the ICU at Complejo Hospitalario Jaén, Spain.
}

The authors have disclosed no conflicts of interest. numerous authors and reflected in EuroSCORE, Parsonnet, and EuroSCORE II prognostic indexes. ${ }^{1-4}$ The majority of these patients are admitted to the ICU before recovering from anesthesia and while under mechanical ventilation, which is generally withdrawn during the first $24 \mathrm{~h}$ unless its continuation is required due to comorbidities or operative/postoperative complications.

Cardiac surgery has become less frequent due to the increased application of percutaneous techniques (eg, per-

\footnotetext{
Correspondence: Eduardo Aguilar-Alonso MD, Hospital Infanta Margarita, Avenida Góngora s/n 14940 Cabra (Córdoba) Spain. E-mail: eaguia@yahoo.es.
}

DOI: $10.4187 /$ respcare.04915 
cutaneous coronary intervention, transcatheter aortic valve implantation, percutaneous valvuloplasty, and percutaneous correction of congenital heart defects). This has led to a change in the profile of cardiac surgery patients, who increasingly have a history of chronic ischemic heart disease, multiple interventions, and non-revascularizable multivessel disease. Consequently, morbidity rates have risen among these patients, associated with longer ICU stays and higher mortality rates. ${ }^{5-9}$ The Society of Thoracic Surgeons describes an ICU stay $>48 \mathrm{~h}$ as long and related to prolonged mechanical ventilation $(>24 \mathrm{~h})$ and an increase in mortality. ${ }^{10}$ An inverse relationship was observed between prolonged mechanical ventilation and short-term survival in critical surgery patients, ${ }^{11}$ and the main predictor of mortality in patients under prolonged mechanical ventilation was found to be multiple organ failure. ${ }^{12}$

Despite the very high mortality among the relatively small percentage of patients who require prolonged mechanical ventilation after cardiac surgery, ${ }^{10,12-14}$ they have not been identified as a group with special care needs. There appears to have been insufficient research on the situation of these patients, as reflected in the minimal space allocated to their treatment in clinical practice guidelines. ${ }^{15-17}$ With this in mind, the objective of this investigation was to evaluate the ICU mortality after cardiac surgery and its relationship to prolonged mechanical ventilation and the management, complications, and treatments of these patients.

\section{Methods}

We conducted a retrospective analysis of a prospective, multi-center, observational study of adults undergoing cardiac surgery at 3 Andalusian hospitals (Virgen del Rocío Hospital in Seville, Puerta del Mar Hospital in Cádiz, and Carlos Haya Hospital in Málaga) between June 2008 and December 2012. Subject information was derived from the database of ARIAM-Andalusía, an observational, prospective, multi-center study of all cardiac surgery patients; this database has progressively incorporated 11 hospitals in the Spanish autonomous community of Andalusia. Data are collected by the physicians in charge of registration and entered into the database by each hospital (via http://www. ccardiaca.org). ARIAM-Andalusía is a global project within the Andalusian Public Health Service that has been partially funded by the regional government since 2005; the database also includes registries on acute coronary syndrome, cardiac arrests, severe sepsis, and pediatric cardiac surgery, among others. The ARIAM database incorporates quality-control software for data that are missing or deviate from preset ranges. ARIAM registries comply with data-protection legislation on the management of medical records, separating data that identify patients from clinical data and preserving patient anonymity. Our study was conducted in accordance with the principles of the

\section{QUICK LOOK}

\section{Current knowledge}

Cardiac surgery mortality is a key quality indicator and an important factor in therapeutic decision-making for eligible patients. Increased mortality in cardiac surgery has been associated with numerous factors, including higher age, female sex, comorbidities, reoperation, and postoperative complications such as sepsis, renal failure, and lung disorders, among others. Hence, there is a need to prioritize this very large number of factors for further in-depth investigation of their impact on mortality in these patients.

\section{What this paper contributes to our knowledge}

Although subjects with prolonged mechanical ventilation represented only $10-20 \%$ of cardiac surgery subjects, the majority of the postoperative mortality was concentrated in this group and is associated with multiple organ failure and sepsis. Our findings suggest that further research is warranted and that important aspects related to prolonged mechanical ventilation should be included in cardiac surgery clinical practice guidelines to assist clinicians in the treatment of these patients.

Helsinki Declaration and was approved by the Provincial Research Ethics Committee of Malaga, Spain.

Data were gathered on clinical and demographic variables, including medical history, date of surgery, EuroSCORE and Simplified Acute Physiologic Score (SAPS) 3 severity of illness scores, ICU complications (see the supplementary materials at http://www.rcjournal.com), length of ICU stay, and ICU mortality.

Continuous variables were expressed as mean $\pm \mathrm{SD}$, ordinal variables as median (interquartile range), and qualitative variables as absolute numbers and percentages. Nonparametric tests were used to compare continuous and ordinal variables, applying the Mann-Whitney test for comparisons of 2 independent samples and the KruskalWallis test for comparisons of 3 or more samples. The chisquare test was used to compare proportions. Binary logistic regression was used for the multivariable analysis, using the stepwise method. $P<.05$ was considered significant.

\section{Results}

The study included 3,588 adults treated at the Carlos Haya Hospital in Malaga (23.3\%), Puerta de Mar Hospital in Cadiz (33.3\%), or Virgen del Rocio Hospital in Seville $(43.4 \%)$. The mean \pm SD age of the sample was $63.5 \pm 12.8$ y, median (interquartile range [IQR]) Euro- 
Table 1. Characteristics of Subjects

\begin{tabular}{lc}
\hline \hline & Total \\
& $(N=3,588)$ \\
\hline Age, y & $63.5 \pm 12.8$ \\
EuroSCORE, points & $5(3-7)$ \\
SAPS 3, points & $41(35-48)$ \\
Length of ICU stay, d & $6.2 \pm 10$ \\
Cardiopulmonary bypass duration, min & $113.8 \pm 50.6$ \\
Operative status, $n(\%)$ & \\
Elective & $3,116(86.8)$ \\
Urgent & $349(9.7)$ \\
Emergency & $123(3.49)$ \\
Surgery type, $n(\%)$ & \\
Coronary artery bypass surgery & $879(24.5)$ \\
Single valve & $1,733(48.3)$ \\
Multiple valves & $306(8.5)$ \\
Valve surgery + CABG & $315(8.8)$ \\
Aorta & $107(3)$ \\
Other & $248(6.9)$ \\
Reoperation & $174(4.8)$ \\
Mechanical ventilation $>$ Ordinal variables are expressed as & \\
\hline Continuous variables are expressed as means \pm (in) \\
medians (interquartile range).
\end{tabular}

SCORE was 5 (3-7), and median (IQR) SAPS 3 score was 41 (35-48). Further subject data are shown in Table 1.

The hospital mortality of these subjects was $10.8 \%$ versus the SAPS 3-predicted hospital mortality of $12.1 \%$. The intraoperative mortality rate was $0.9 \%$, and the ICU mortality rate was $7.9 \%$. Mortality at $30 \mathrm{~d}$ was $9.2 \%$ versus the EuroSCORE prediction of $7.3 \%$; mortality at $30 \mathrm{~d}$ among subjects undergoing coronary artery bypass graft surgery $(n=879)$ was $3.6 \%$ versus the EuroSCORE prediction of $3.5 \%$. Mortality at $30 \mathrm{~d}$ among subjects undergoing single-valve surgery $(n=1,733)$ was $7.3 \%$ versus the EuroSCORE prediction of $7.3 \%$. Mortality at $30 \mathrm{~d}$ among the 976 subjects undergoing other surgeries (ie, multiple valve surgery, coronary artery bypass graft surgery with valve surgery, or aortic dissection, among others) was $17.7 \%$ versus the EuroSCORE prediction of $10.4 \%$. The surgery was emergent in $10.2 \%$ of this group of 976 subjects versus $0.8 \%$ in the 2,612 subjects undergoing coronary artery bypass graft surgery or single-valve surgery $(P<.001)$.

Subject characteristics shown in Table 2 show that subjects who died in hospital were older, had more severe illness, and underwent cardiovascular bypass of longer duration compared to subjects who did not die in hospital. The mortality was higher in subjects undergoing urgent or emergent surgery versus elective surgery.

The ICU mortality rate was $44.3 \%(n=184)$ among the 415 subjects ( $11.6 \%$ of total sample) who required prolonged mechanical ventilation (due to impossibility of with- drawal within $24 \mathrm{~h}$ or need for re-intubation) versus $3.1 \%$ $(n=99)$ of the 3,173 subjects who did not require prolonged mechanical $(P<.001)$. Among the 283 subjects who died in the ICU, 184 (5.9\% of total sample) received mechanical ventilation for $>24 \mathrm{~h}$, while 99 (2.8\% of total) did not. Table 3 displays the characteristics of the subjects who received or did not receive prolonged postoperative mechanical ventilation; no age difference was observed between these 2 groups, but the former had greater severity of illness per EuroSCORE and SAPS 3 and a longer ICU length of stay. Table 3 also shows that prolonged mechanical ventilation was significantly associated with pneumonia, re-intervention, renal failure, sepsis, multiple organ failure, bleeding of $>1,000 \mathrm{~mL}$, cardiogenic shock, cardiopulmonary bypass duration $>120$ min, surgery type, cardiac arrest in ICU, ICU mortality, and hospital mortality. With regard to the type of surgery, prolonged mechanical ventilation was recorded in $6.7 \%$ of the 879 subjects receiving coronary artery bypass graft surgery, in $9.3 \%$ of the 1,733 subjects undergoing single-valve surgery, and in $20 \%$ of the 976 undergoing multiple-valve surgery, coronary artery bypass graft surgery with valve surgery, aortic dissection, or other surgeries.

With regard to the EuroSCORE results, prolonged mechanical ventilation was performed in $4.5 \%(n=61)$ of the 1,350 subjects with EuroSCORE $<4$, in $11.2 \%$ $(n=162)$ of the 1,451 subjects with EuroSCORE of 4-7, in $21.2 \%(n=119)$ of the 560 subjects with EuroSCORE of $7-10$, and in $32.2 \%(n=73)$ of the 227 subjects with EuroSCORE $>10$.

Prolonged mechanical ventilation was significantly associated with history of COPD (17.1\% of 415 subjects with prolonged mechanical ventilation vs $8.2 \%$ of 3,173 subjects without, $P<.001)$; smoking habit $(21.4 \%$ vs $16.1 \%$, $P=.006)$; and history of stroke $(8.4 \%$ vs $5.2 \%, P=.007)$. Prolonged mechanical ventilation was not significantly associated with a history of diabetes, hypertension, or obesity.

Table 4 reports data on 3 groups of subjects: ICU survivors, ICU non-survivors who received prolonged mechanical ventilation, and ICU non-survivors who did not receive prolonged mechanical ventilation. The severity of illness calculated per EuroSCORE was significantly higher in both groups of ICU non-survivors than in ICU survivors, with no difference between the ICU non-survivor groups. All 3 groups significantly differed in SAPS 3-evaluated severity and in the duration of extracorporeal circulation (longer in those receiving prolonged mechanical ventilation). Differences were also observed in the frequency of bleeding and reoperations.

Table 5 exhibits the results of multivariable analysis with ICU mortality as a dependent variable and EuroSCORE and SAPS 3 scores, bypass surgery $>120 \mathrm{~min}$, and surgery type (elective vs non-elective) as independent variables. ICU mortality was $>15$-fold more likely in 
Table 2. Relationship Between Hospital Mortality and Other Variables

\begin{tabular}{|c|c|c|c|}
\hline & Survivors $(n=3,130)$ & Non-survivors $(n=379)$ & $P$ \\
\hline Age, y & $63.1 \pm 12.8$ & $66.2 \pm 12.6$ & $<.001$ \\
\hline EuroSCORE, points & $5(3-7)$ & $7(6-10)$ & $<.001$ \\
\hline SAPS 3, points & $40(35-47)$ & $51(44-60)$ & $<.001$ \\
\hline Length of ICU stay, $d$ & $5.5 \pm 6.5$ & $11.7 \pm 24.3$ & $<.001$ \\
\hline Cardiopulmonary bypass duration, min & $108.6 \pm 43$ & $159.1 \pm 80.8$ & $<.001$ \\
\hline Operative status, $n / n(\%)$ & & & $<.001$ \\
\hline Elective $(n=3,045)$ & $2,786 / 3,130(89)$ & $259 / 379(68.3)$ & \\
\hline Urgent $(n=343)$ & $273 / 3,130(8.7)$ & $70 / 379(18.5)$ & \\
\hline Emergency $(n=121)$ & $71 / 3,130(2.3)$ & $50 / 379(13.2)$ & \\
\hline Surgery type, $n / n(\%)$ & & & $<.001$ \\
\hline $\mathrm{CABG}(n=849)$ & $813 / 3,130(25.97)$ & $36 / 379(9.5)$ & \\
\hline Single valve $(n=1,704)$ & $1,551 / 3,130(49.5)$ & $153 / 379(40.4)$ & \\
\hline Multiple valve $(n=299)$ & $227 / 3,130(7.25)$ & $72 / 379(19)$ & \\
\hline Valve surgery + CABG $(n=308)$ & $262 / 3,130(8.4)$ & $46 / 379(12.1)$ & \\
\hline Aorta $(n=106)$ & $76 / 3,130(2.4)$ & $30 / 379(7.9)$ & \\
\hline Others $(n=243)$ & $201 / 3,130(6.4)$ & $42 / 379(11.1)$ & \\
\hline Reoperation, $n / n(\%)$ & $122 / 3,130(3.9)$ & $51 / 379(13.45)$ & $<.001$ \\
\hline Mechanical ventilation $>24 \mathrm{~h}, n / n(\%)$ & $207 / 3,130(6.6)$ & $203 / 379(53.6)$ & $<.001$ \\
\hline Cardiogenic shock, $n / n(\%)$ & $133 / 3,130(4.2)$ & $173 / 379(45.6)$ & $<.001$ \\
\hline Cardiac arrest in ICU, $n / n(\%)$ & $23 / 3,130(0.73)$ & $109 / 379(28.8)$ & $<.001$ \\
\hline Cardiopulmonary bypass duration $>120 \mathrm{~min}, n / n(\%)$ & $937 / 3,130(29.9)$ & $222 / 379(58.6)$ & $<.001$ \\
\hline Renal failure, $n / n(\%)$ & $681 / 3,130(21.8)$ & $245 / 379(64.6)$ & $<.001$ \\
\hline Sepsis, $n / n(\%)$ & $53 / 3,130(1.7)$ & $72 / 379(19)$ & $<.001$ \\
\hline Multiple organ failure, $n / n(\%)$ & $22 / 3,130(0.7)$ & $142 / 379(37.5)$ & $<.001$ \\
\hline \multicolumn{4}{|c|}{$\begin{array}{l}\text { Data on hospital mortality are missing for } 79(2.2 \%) \text { of the } 3,588 \text { subjects. Continuous variables are expressed as means } \pm \text { SD. Ordinal variables are expressed as medians (interquartile range). } \\
\text { Multiple organ failure }=\geq 2 \text { major organ systems with compromised function } \\
\text { SAPS = Simplified Acute Physiologic Score } \\
\text { CABG = coronary artery bypass graft }\end{array}$} \\
\hline
\end{tabular}

subjects who required prolonged mechanical ventilation than in those who did not (odds ratio 15.19, 95\% CI 11.56-22.09). This table also shows the results obtained when ICU complications (eg, cardiogenic shock, renal failure, multiple organ failure, sepsis) were entered into the model as independent variables, which reduced the odds ratio for ICU mortality in these subjects from 15.19 to 3.07 (95\% CI 1.9-4.94), suggesting that these variables may be responsible for a large part of the ICU mortality in subjects receiving prolonged postoperative mechanical ventilation.

Table 6 shows that the main cause of death recorded by the attending physician was sepsis or multiple organ failure in ICU non-survivors who received prolonged mechanical ventilation and cardiogenic shock in those who did not. These data are consistent with the results of the 2 multivariable analyses, which found that sepsis and multiple organ failure were primarily responsible for the ICU mortality in the subjects undergoing prolonged postoperative mechanical ventilation. Given these findings, we analyzed data on cultures available from one of the participating hospitals, because the ARIAM database does not routinely incorporate information on follow-up cultures.
According to these data, at least 1 culture was positive in $43(58.1 \%)$ of the 73 subjects who required prolonged mechanical ventilation in this hospital, while 2 or more cultures were positive in 19 (26\%) of them. Positive cultures were most frequently from pulmonary secretions $(42.3 \%)$, followed by samples from the urinary tract $(23 \%)$, blood (21.6\%), and surgical wound $(9.5 \%)$. The length of ICU stay was $>5 \mathrm{~d}$ in $51(69.8 \%)$ of these 73 subjects, and at least 1 culture was positive in $36(70.6 \%)$ of them. According to ARIAM data, 17 (23\%) of the 73 subjects requiring prolonged ventilation developed sepsis during their ICU stay, with 1 positive culture in 14 $(82.4 \%)$ of these 17 subjects and $>2$ positive cultures in $12(70.6 \%)$ of them, most frequently from pulmonary secretions $(82.4 \%)$ and blood $(41.2 \%)$. There was at least 1 positive culture for $15(62.5 \%)$ of the 24 subjects in this hospital who died from sepsis or multiple organ failure.

\section{Discussion}

In this study, a relatively small percentage (10-15\%) of subjects admitted to the ICU after cardiac surgery required 
Table 3. Relationship Between Prolonged Mechanical Ventilation and Other Variables

\begin{tabular}{|c|c|c|c|}
\hline & $\begin{array}{l}\text { With Mechanical } \\
\text { Ventilation }>24 \mathrm{~h}(n=415)\end{array}$ & $\begin{array}{c}\text { Without Mechanical } \\
\text { Ventilation }>24 \mathrm{~h}(n=3,173)\end{array}$ & $P$ \\
\hline Age, y & $63.7 \pm 13.8$ & $63.4 \pm 12.7$ & .12 \\
\hline EuroSCORE, points & $7(6-10)$ & $5(3-7)$ & $<.001$ \\
\hline SAPS 3, points & $49(41-57)$ & $40(35-47)$ & $<.001$ \\
\hline Length of ICU stay, $d$ & $16.4 \pm 23.8$ & $4.8 \pm 4.7$ & $<.001$ \\
\hline Surgery type, $n(\%)$ & & & $<.001$ \\
\hline CABG & $59(14.2)$ & $820(25.8)$ & \\
\hline Single valve & $161(38.8)$ & $1572(49.5)$ & \\
\hline Multiple valve & $63(15.2)$ & $243(7.7)$ & \\
\hline Valve surgery $+\mathrm{CABG}$ & $57(13.7)$ & $258(8.2)$ & \\
\hline Aorta & $38(9.2)$ & $69(2.2)$ & \\
\hline Others & $37(8.9)$ & $211(6.6)$ & \\
\hline Bleeding $>1,000 \mathrm{~mL}, n(\%)$ & $182(43.8)$ & $390(12.3)$ & $<.001$ \\
\hline Reoperation, $n(\%)$ & 98 (23.6) & $76(2.4)$ & $<.001$ \\
\hline Renal failure, $n(\%)$ & $302(72.8)$ & $635(20)$ & $<.001$ \\
\hline Pneumonia, $n(\%)$ & $100(24.1)$ & $19(0.6)$ & $<.001$ \\
\hline Multiple organ failure, $n(\%)$ & $127(30.6)$ & $39(1.2)$ & $<.001$ \\
\hline Cardiopulmonary bypass duration $>120 \mathrm{~min}, n(\%)$ & $259(62.4)$ & $923(29.1)$ & $<.001$ \\
\hline Cardiogenic shock, $n(\%)$ & $174(41.9)$ & $135(4.2)$ & $<.001$ \\
\hline Sepsis, $n(\%)$ & $103(24.8)$ & $24(0.75)$ & $<.001$ \\
\hline Cardiac arrest in ICU, $n(\%)$ & $83(20)$ & $49(1.5)$ & $<.001$ \\
\hline Death in ICU, $n(\%)^{*}$ & $184(44.3)$ & $99(3.1)$ & $<.001$ \\
\hline Death in hospital, $n(\%)^{\dagger}$ & $203(48.9)$ & $176(5.5)$ & $<.001$ \\
\hline \multicolumn{4}{|c|}{$\begin{array}{l}\text { Continuous variables are expressed as means } \pm \text { SD. Ordinal variables are expressed as medians (interquartile range). } \\
\text { *ICU mortality (with mechanical ventilation }>24 \mathrm{~h}: 44.3 \% \text {; without mechanical ventilation }>24 \mathrm{h:} 3.1 \% \text { ). } \\
\text { "Missing } 79(2.2 \%) \text { of } 3,588 \text { subjects. Hospital mortality (with mechanical ventilation }>24 \mathrm{~h}: 49.5 \% \text {; without mechanical ventilation }>24 \mathrm{~h}: 5.7 \% \text { ). } \\
\text { Multiple organ failure }=\geq 2 \text { major organ systems with compromised function } \\
\text { SAPS = Simplified Acute Physiologic Score } \\
\text { CABG = coronary artery bypass graft }\end{array}$} \\
\hline
\end{tabular}

Table 4. Relationship of ICU Mortality With Prolonged Mechanical Ventilation and Other Variables

\begin{tabular}{|c|c|c|c|c|}
\hline & $\begin{array}{l}\text { ICU Survivors } \\
(n=3,305)\end{array}$ & $\begin{array}{c}\text { ICU Non-survivors } \\
\text { Without Mechanical } \\
\text { Ventilation }>24 \mathrm{~h}(n=99)\end{array}$ & $\begin{array}{c}\text { ICU Non-survivors } \\
\text { With Mechanical } \\
\text { Ventilation }>24 \mathrm{~h}(n=184)\end{array}$ & $P$ \\
\hline Age, y & $63.2 \pm 12.7$ & $68.3 \pm 12.3$ & $64.8 \pm 13.6$ & $<.001$ \\
\hline EuroSCORE, points & $5(3-7)$ & $7(6-10)$ & $8(6-10)$ & $<.001$ \\
\hline SAPS 3, points & $40(35-47)$ & $53(47-74)$ & $51(44-59)$ & $<.001$ \\
\hline Cardiopulmonary bypass duration, min & $109.8 \pm 45.1$ & $146.3 \pm 71.33$ & $167 \pm 82.9$ & $<.001$ \\
\hline Length of ICU stay, d & $5.7 \pm 6.8$ & $5.3 \pm 6.8$ & $15.7 \pm 31.4$ & $<.001$ \\
\hline Bleeding $>1,000 \mathrm{~mL}, n(\%)$ & $456(13.8)$ & $41(41.4)$ & $75(40.7)$ & $<.001$ \\
\hline Reoperation, $n(\%)$ & $131(3.9)$ & $11(11.1)$ & $32(17.4)$ & $<.001$ \\
\hline
\end{tabular}

$\overline{\text { Continuous variables }}$ are expressed as means \pm SD. Ordinal variables are expressed as medians (interquartile range).

prolonged mechanical ventilation $(>24 \mathrm{~h})$. However, a very high percentage of these subjects died, mainly due to renal failure, multiple organ failure, or sepsis, among other complications, representing two thirds of the ICU mortality in all cardiac surgery subjects. The most frequent cause of death in those who did not require prolonged mechanical ventilation was cardiogenic shock, which was more directly linked to the surgery and a history of heart disease.
Higher age, female sex, low ejection fraction, diabetes, peripheral vascular disease, immunosuppression, renal failure, urgent or emergency surgery, a history of cardiac surgery, and the performance of prolonged bypass surgery, non-elective surgery, reoperation, and combined surgery have all been associated with mortality in cardiac surgery patients. ${ }^{8-10,12,14,18-20}$. Postoperative factors related to mortality include sepsis, renal failure, myocardial infarction, 
Table 5. Multivariable Logistic Regression Analysis With ICU Mortality as Dependent Variable

\begin{tabular}{lc}
\hline \multicolumn{1}{c}{ Variable } & $\begin{array}{c}\text { Odds Ratio } \\
(95 \% \mathrm{CI})\end{array}$ \\
\hline $\begin{array}{l}\text { Model: Not including ICU complications } \\
\text { Mechanical ventilation }>24 \mathrm{~h}\end{array}$ & $15.19(11.56-22.09)$ \\
EuroSCORE & $1.11(1.05-1.18)$ \\
SAPS 3 & $1.09(1.07-1.1)$ \\
Cardiopulmonary bypass duration $>120$ min & $2.01(1.45-2.78)$ \\
Non-elective surgery & $2.88(1.82-4.58)$ \\
Model: Including ICU complications & \\
Mechanical ventilation $>24 \mathrm{~h}$ & $3.07(1.9-4.94)$ \\
EuroSCORE & $1.17(1.08-1.26)$ \\
SAPS 3 & $1.04(1.02-1.07)$ \\
Cardiopulmonary bypass duration $>120$ min & $2.01(1.30-3.11)$ \\
Non-elective surgery & $2.29(1.23-3.11)$ \\
Cardiogenic shock & $3.78(2.32-6.15)$ \\
Cardiac arrest in ICU & $35.5(19.05-66.17)$ \\
Renal failure & $2.14(1.1-4.07)$ \\
Multiple organ failure & $16.99(9.33-30.94)$ \\
Sepsis & $2.11(1.1-4.07)$ \\
\hline Multiple organ failure $=\geq 2$ major organ systems with compromised function \\
SAPS = Simplified Acute Physiologic Score \\
\hline
\end{tabular}

stroke, and cardiac arrest, among other complications, and the utilization of intra-aortic balloon pump and prolonged mechanical ventilation. Pulmonary complications implicated in the increased morbidity and mortality among cardiac surgery patients include pleural effusion, pneumonia, atelectasis, weaning difficulties, diaphragm dysfunction, and ARDS, among others. ${ }^{21-22}$ In addition, withdrawal of mechanical ventilation can be challenging in patients with chronic valve disease or adult congenital heart disease, who often present with pulmonary hypertension. Given this very large number of prognostic factors, there is a need to prioritize them for further in-depth investigation of their impact on mortality in these patients.

Our study focused on prolonged mechanical ventilation after cardiac surgery as a factor with an important influence on outcomes. Many authors have reported a relationship between prolonged mechanical ventilation and higher mortality and severity after cardiac surgery, ${ }^{10-12,23}$ as observed in this study, although other researchers have found that extubation failure and re-intubation were linked to prolongation of mechanical ventilation but not to mortality. ${ }^{24}$

In our investigation, prolonged mechanical ventilation was associated with greater severity of illness (eg, a higher EuroSCORE), in line with previous reports. ${ }^{23} \mathrm{We}$ also found that the percentage of subjects receiving prolonged mechanical ventilation varied according to the type of surgery, ranging from $6.7 \%$ after coronary artery bypass graft surgery and $9.3 \%$ after single-valve surgery to $20 \%$ after multiple-valve surgery.

Discrepancies among published studies in the percentage of subjects requiring prolonged mechanical ventilation and in mortality rates may be explained by differences in the definition of prolonged mechanical ventilation (24, 48 or $72 \mathrm{~h}$ ). Mortality rates have varied widely among studies, reaching percentages similar to or even higher than the $40 \%$ observed in this investigation. ${ }^{25-26}$

Our findings serve to highlight a specific and relatively small population of patients with a very high mortality (ie, those receiving mechanical ventilation for $>24 \mathrm{~h}$ ). This is a readily identifiable group of patients whose causes of death were found to be distinct from those observed in patients who do not require mechanical ventilation for this length of time. Knowledge of the factors associated with mortality in these patients is of major interest.

When we controlled for ICU admission variables in the multivariable analysis, the mortality rate was 15.19 -fold higher in subjects who required prolonged mechanical ventilation than in those who did not. When variables related to the ICU length of stay were considered in a second multivariable analysis, the mortality rate was 3.07 -fold higher in those requiring prolonged mechanical ventilation. These findings suggest that mortality in those undergoing prolonged ventilation was largely attributable to postoperative complications, including cardiogenic shock, cardiac arrest, renal failure, multiple organ failure, and sepsis.

We also investigated the main cause of death attributed by the attending physician, finding it to be sepsis or multiple organ failure in those who required mechanical ventilation and cardiogenic shock in those who did not. Sepsis and multiple organ failure entered the second multivariable analysis and showed high odds ratio values. These, together with the results of the 2-stage multivariable analysis, confirm that the mortality rate in subjects requiring prolonged mechanical ventilation was largely due to sepsis and multiple organ failure, as well as cardiogenic shock. It has been reported previously that sepsis and multiple organ failure are associated with mortality in cardiac surgery patients requiring prolonged mechanical ventilation. ${ }^{27-28}$

In this study, we observed a higher frequency of pneumonia in those who underwent prolonged mechanical ventilation than in those who did not. Kollef et al ${ }^{12}$ reported that $22.7 \%$ of their series of 472 cardiac surgery subjects required prolonged mechanical ventilation and that the mortality rate in this group was mainly due to multiple organ failure, associated with antibiotic-resistant infection and pneumonia. The appropriate antibiotics treatment of complications such as sepsis is known to have a considerable impact on mortality. ${ }^{29-30}$ Acute renal failure was also more frequent in subjects who received prolonged mechanical ventilation, and a higher mortality rate has been observed 
Table 6. Relationship Between Mechanical Ventilation $>24 \mathrm{~h}$ and Cause of Death

\begin{tabular}{lcc}
\hline \hline & $\begin{array}{c}\text { ICU Non-Survivors Without Mechanical } \\
\text { Ventilation }>24 \mathrm{~h}(n=99)\end{array}$ & $\begin{array}{c}\text { ICU Non-Survivors With Mechanical } \\
\text { Ventilation }>24 \mathrm{~h}(n=184)\end{array}$ \\
\hline Cardiogenic shock, $n(\%)$ & $58(59.2)$ & $65(35.5)$ \\
Pulseless electrical activity, $n(\%)$ & $4(4.1)$ & $1(0.5)$ \\
Asystole, $n(\%)$ & $8(8.2)$ & $7(3.8)$ \\
Ventricular fibrillation, $n(\%)$ & $1(1)$ & $1(0.5)$ \\
Multiple organ failure-sepsis, $n(\%)$ & $11(11.2)$ & $92(50.3)$ \\
Encephalopathy, $n(\%)$ & $2(2)$ & $8(4.4)$ \\
Cardiac tamponade, $n(\%)$ & $4(4.1)$ & $0(0)$ \\
Other, $n(\%)$ & $8(8.2)$ & $9(4.9)$ \\
Not known, $n(\%)$ & $2(2)$ & $0(0)$ \\
Statistically significant differences by the chi-square test. & & \\
\end{tabular}

in acute renal failure patients requiring renal replacement therapy. ${ }^{31-32}$ We also observed a relationship between prolonged mechanical ventilation and reoperation, as previously reported, which has been related to increased mortality rates. ${ }^{33-35}$

Prolonged mechanical ventilation was associated with greater preoperative severity of illness as measured by EuroSCORE and with the type of surgery performed. There is a need to optimize the assessment of pre- and postoperative risk in these patients, especially in those undergoing more complex surgeries. EuroSCORE II, ${ }^{4}$ which was not available at the start of our study, includes a correction factor for the type and number of surgical interventions (isolated coronary artery bypass graft surgery as reference category and odds ratios of 1.006 for 1 non-coronary artery bypass graft surgery procedure, 1.74 for 2 procedures, and 2.64 for 3 procedures).

Our retrospective analysis of the prospectively gathered information represents a potential study limitation. For instance, it would have been of interest to consider data that allow calculation of the subjects' Sequential Organ Failure Assessment Score (SOFA), ${ }^{36}$ although we were able to evaluate multiple organ failure in a different manner (see the supplementary materials at http://www.rcjournal.com). It would also have been useful to evaluate the limitation of therapeutic effort, among other aspects. In addition, the 30-d mortality rate in our series was higher than predicted by EuroSCORE overall (9.2\% vs 7.6\%), although this increase was mainly observed in the subjects undergoing complex procedures such as multiple-valve surgery, coronary artery bypass graft surgery with valve surgery, and aortic dissection, among others (17.68\% vs $10.36 \%$ ), which are frequent in the 3 participating regional reference centers. The $30-\mathrm{d}$ mortality rate was similar to the EuroSCORE prediction in those undergoing coronary artery bypass graft surgery or single valve surgery. In contrast, the hospital mortality rate in our subjects $(10.8 \%)$ was lower than that predicted by SAPS 3 (12.19\%).
This study contributes evidence on the high morbidity and mortality rates associated with prolonged mechanical ventilation. Clinical practice guidelines ${ }^{15-17}$ appear to pay inadequate attention to this issue, which warrants further investigation to improve outcomes among this specific group of patients.

\section{Conclusions}

Within the limitations of our study, we conclude that the small minority of patients receiving prolonged mechanical ventilation after cardiac surgery represents a specific group in which most of the postsurgery mortality is concentrated. We believe that greater attention needs to be paid to the treatment of cardiac surgery patients who require prolonged mechanical ventilation. Further research on this issue is warranted, and there is a need to include important aspects related to prolonged mechanical ventilation in cardiac surgery clinical practice guidelines to assist clinicians in the treatment of these patients.

\section{REFERENCES}

1. Parsonnet V, Dean D, Bernstein AD. A method of uniform stratification of risk for evaluating the results of surgery in acquired adult heart disease. Circulation 1989;79(6 Pt 2):I3-I12.

2. Nashef SA, Roques F, Michel P, Gauducheau E, Lemeshow S, Salamon R. European system for cardiac operative risk evaluation (EuroSCORE). Eur J Cardiothorac Surg 1999;16(1):9-13.

3. Gogbashian A, Sedrakyan A, Treasure T. EuroSCORE: a systematic review of international performance. Eur J Cardiothorac Surg 2004; 25(5):695-700.

4. Nashef SA, Roques F, Sharples LD, Nilsson J, Smith C, Goldstone AR, et al. EuroSCORE II. Eur J Cardiothorac Surg. 2012; 41(4):734-744.

5. Higgins TL, Estafanous FG, Loop FD, Beck GJ, Blum JM, Paranandi L. Stratification of morbidity and mortality outcome by preoperative risk factors in coronary artery bypass patients. A clinical severity score. JAMA 1992;267(17):2344-2348.

6. Ferguson TB Jr., Hammill BG, Peterson ED, DeLong ER, Grover FL; STS National Database Committee. A decade of change-risk 
profiles and outcomes for isolated coronary artery bypass grafting procedures, 1990-1999: a report from the STS National Database Committee and the Duke Clinical Research Institute. Society of Thoracic Surgeons. Ann Thorac Surg 2002;73(2):480-489.

7. Vranken NP, Weerwind PW, Barenbrug PJ, Teerenstra S, Ganushchak YM, Maessen JG. The role of patient's profile and allogeneic blood transfusion in development of post-cardiac surgery infections: a retrospective study. Interact Cardiovasc Thorac Surg 2014;19(2):232-238.

8. Heimrath OP, Buth KJ, Légaré JF. Long-term outcomes in patients requiring stay of more than 48 hours in the intensive care unit following coronary bypass surgery. J Crit Care 2007;22(2):153-158.

9. Gersbach P, Tevaearai H, Revelly JP, Bize P, Chiolero R, von Segesser LK. Are there accurate predictors of long-term vital and functional outcomes in cardiac surgical patients requiring prolonged intensive care? Eur J Cardiothorac Surg 2006;29(4):466-472.

10. LaPar DJ, Gillen JR, Crosby IK, Sawyer RG, Lau CL, Kron IL, et al. Predictors of operative mortality in cardiac surgical patients with prolonged intensive care unit duration. J Am Coll Surg 2013;216(6): 1116-1123.

11. Schneider CP, Fertmann J, Miesen J, Wolf H, Flexeder C, Hofner B, et al. Short-term prognosis of critically ill surgical patients: the impact of duration of invasive organ support therapies. J Crit Care 2012;27(1):73-82.

12. Kollef MH, Wragge T, Pasque C. Determinants of mortality and multiorgan dysfunction in cardiac surgery patients requiring prolonged mechanical ventilation. Chest 1995;107(5):1395-1401.

13. Cameron D. Initiation of white cell activation during cardiopulmonary bypass: cytokines and receptors. J Cardiovasc Pharmacol 1996; 27(Suppl 1):S1-S5.

14. Algarni KD, Elhenawy AM, Maganti M, Collins S, Yau TM. Decreasing prevalence but increasing importance of left ventricular dysfunction and reoperative surgery in prediction of mortality in coronary artery bypass surgery: trends over 18 years. J Thorac Cardiovasc Surg 2012;144(2):340-346.

15. Carl M, Alms A, Braun J, Dongas A, Erb J, Goetz A, et al. S3 guidelines for intensive care in cardiac surgery patients: hemodynamic monitoring and cardiocirculary system. Ger Med Sci. 2010;8:Doc12.

16. Vahanian A, Alfieri O, Andreotti F, Antunes MJ, Baron-Esquivias $\mathrm{G}$, Baumgarter $\mathrm{H}$, et al. Guidelines on the management of valvular heart disease (version 2012). Joint Task Force on the Management of Valvular Heart Disease of the European Society of Cardiology (ESC); European Association for Cardio-Thoracic Surgery (EACTS), Eur Heart J 2012;33(19):2451-2496.

17. 2012 Writing Committee Members, Jneid H, Anderson JL, Wright RS, Adams CD, Bridges CR, Casey DE Jr., et al. American College of Cardiology Foundation; American Heart Association Task Force on Practice Guidelines. 2012 ACCF/AHA focused update of the guideline for the management of patients with unstable angina/NonST-elevation myocardial infarction (updating the 2007 guideline and replacing the 2011 focused update): a report of the American College of Cardiology Foundation/American Heart Association Task Force on practice guidelines. Circulation. 2012;14:126(7):875-910.

18. Shahian DM, O'Brien SM, Filardo G, Ferraris VA, Haan CK, Rich JB, et al. Society of Thoracic Surgeons Quality Measurement Task Force. The Society of Thoracic Surgeons 2008 cardiac surgery risk models: part 3-valve plus coronary artery bypass grafting surgery. Ann Thorac Surg 2009;88(1 Suppl):S43-S62.

19. Frank E. Silvestry. Postoperative complications among patients undergoing cardiac surgery. June 2, 2017. http://www.uptodate.com. Accessed December 13, 2017.

20. Curiel-Balsera E, Mora-Ordoñez JM, Castillo-Lorente E, BenitezParejo J, Herruzo-Avilés A, Ravina-Sanz JJ, et al. Mortality and complications in elderly patients undergoing cardiac surgery. J Crit Care 2013;28(4):397-404.

21. Peng MJ, Vargas FS, Cukier A, Terra-Filho M, Teixeira LR, Light RW. Postoperative pleural changes after coronary revascularization. Comparison between saphenous vein and internal mammary artery grafting. Chest 1992;101(2):327-330.

22. Messent M, Sullivan K, Keogh BF, Morgan CJ, Evans TW. Adult respiratory distress syndrome following cardiopulmonary bypass: incidence and prediction. Anaesthesia 1992;47(3):267-268.

23. Filsoufi F, Rahmanian PB, Castillo JG, Chikwe J, Adams DH. Predictors and early and late outcomes of respiratory failure in contemporary cardiac surgery. Chest 2008;133(3):713-721.

24. Rady MY, Ryan T. Perioperative predictors of extubation failure and the effect on clinical outcome after cardiac surgery. Crit Care Med 1999;27(2):340-347

25. Trouillet JL, Combes A, Vaissier E, Luyt CE, Ouattara A, Pavie A, et al. Prolonged mechanical ventilation after cardiac surgery: outcome and predictors. J Thorac Cardiovasc Surg 2009;138(4):948-953.

26. LoCicero J 3rd, McCann B, Massad M, Joob AW. Prolonged ventilatory support after open-heart surgery. Crit Care Med 1992;20(7): 990-992.

27. J Hortal, P Muñoz, G Cuerpo, H Livtan, P M Rosseel, E Bouza, for the European Study Group on Nosocomial Infections and for the European Workgroup of Cardiothoracic Intensivists. Ventilator-associated pneumonia in patients undergoing major heart surgery: an incidence study in Europe. Crit Care 2009;13:R80.

28. E Bouza, J Hortal, P Muñoz, MJ Pérez, MJ Riesgo, M Hiesmayr, on behalf of the European Study Group on Nosocomial Infections and for the European Workgroup of Cardiothoracic Intensivists. Infections following major heart surgery in European intensive care units: there is room for improvement (ESGNI 007 Study). J Hosp Infect 2006;63(4):399-405.

29. Gaieski DF, Mikkelsen ME, Band RA, Pines JM, Massone R, Furia FF et al. Impact of time to antibiotics on survival in patients with severe sepsis or septic shock in whom early goal directed therapy was initiated in the emergency department. Crit Care Med 2010; 38(4):1045-1053.

30. Dellinger RP, Levy MM, Rhodes A, Annane D, Gerlach H, Opal SM, et al. Surviving sepsis campaign: international guidelines for management of severe sepsis and septic shock: 2012. Crit Care Med 2013;41(2):580-637.

31. Bagshaw SM, George C, Dinu I Bellomo R. A multi-centre evaluation of the RIFLE criteria for early acute kidney injury in critically ill patients. Nephrol Dial Transplant 2008;23(4):1203-1210.

32. Ostermann M, Chang RW. Acute kidney injury in the intensive care unit according to RIFLE. Crit Care Med 2007;35(8):1837-1843.

33. Moulton MJ, Creswell LL, Mackeey ME Cox JL, Rosenbloom M. Reexploration for bleeding is a risk factor for adverse outcomes after cardiac operations. J Thorac Cardiovasc Surg 1996;111:1037-1046.

34. Mehta RH, Sheng S, O'Brien SM, Grover FL, Gammie JS, Ferguson $\mathrm{TB}$, et al.. Reoperation for bleeding in patients undergoing coronary artery bypass surgery: incidence, risk factors, time trends, and outcomes Circ Cardiovasc Qual Outcomes 2009;2:583-590.

35. Biancari F, Mikkola R, Heikkinen J, Lahtinen J, Airaksinen KE, Juvonen T. Estimating the risk of complications related to re-exploration for bleeding after cardiac surgery: a systematic review and meta-analysis. European J cardio Thorac Surg 2012;41:50-55.

36. Vincent JL, de Mendonça A, Cantraine F, Moreno R, Takala J, Suter $\mathrm{PM}$, et al. Use of the SOFA score to assess the incidence of organ dysfunction/failure in intensive care units: results of a multicenter, prospective study. Working Group on "sepsis-related problems" of the European Society of Intensive Care Medicine. Crit Care Med 1998; 26(11):1793-1800. 